\title{
Analysis of Innovations in Concentration of Solar Radiation
}

\author{
Elhadj Ali Aoudou ${ }^{1}$, Benoit Ndzana ${ }^{2}$ \\ ${ }^{1}$ Postgraduate School of Science, Technology and Geoscience, Research and Postgraduate Training Unit in Engineering and Its Applications, \\ University of Yaounde 1, Yaounde, Cameroon \\ ${ }^{2}$ Department of Electrical Engineering and Telecommunications, National Advance School of Engineering, Yaounde, Cameroon
}

Email address:

aliaoudou1952@yahoo.com (E. A. Aoudou), bendzana@gmail.com (B. Ndzana)

\section{To cite this article:}

Elhadj Ali Aoudou, Benoit Ndzana. Analysis of Innovations in Concentration of Solar Radiation. American Journal of Science, Engineering and Technology. Vol. 5, No. 1, 2020, pp. 42-47. doi: 10.11648/j.ajset.20200501.15

Received: January 9, 2020; Accepted: March 6, 2020; Published: March 31, 2020

\begin{abstract}
As part of my research work carried out successfully at the level of Master 2 in 2016, in the laboratory of Electrical Engineering, Mechatronics and Signal Processing, I designed a TVS central, which allowed me to replace the use of diesel fuel by solar energy in the production of electrical energy. This solar power plant was named: TVS system. Its solar energy collector is parabolic and well suited to urban areas. I have noticed that its installation, operation and maintenance are complex and require good training for officers working at the plant. The rural area is not electrified in Cameroon it has been very interesting to extend the use of the TVS system in rural areas since water and the sun being available in these places, it will work with steam which will allow to have a $\mathrm{kW}$ at lower cost. It will be a question for me in the context of performance research in the production of electricity, to redesign the TVS system with innovative solar energy collection equipment which also allows to add a thermal storage system to overcome lack of sunshine at night. The process of producing electricity from solar radiation is complex for concentrated solar energy, but direct for voltaic panels. Since the solar energy is not very dense, it is necessary to concentrate it to obtain exploitable temperatures for the production of high-power electricity. These sought temperatures are between $400^{\circ} \mathrm{C}$ and $600^{\circ} \mathrm{C}$. Figure 1 below shows the capture of solar radiation and the movements of the thermal energy received until its transformation into mechanical movement driving the alternator. The solar energy production sector has become dynamic all over the world and we are witnessing various promising innovations which will announce the primordial place that renewable energies will occupy in the near future. Today, solar energy is estimated at $19 \%$ of the world's electric energy. During my thesis work, I propose to: analyze of innovations in concentration of solar radiation. [10]
\end{abstract}

Keywords: Energy-solar, Sensors, Electricity Generation, Optical System, Innovations, Prospects

\section{Introduction}

The world has known for more than a century an important economic, social and industrial development besides it is illustrated by an ever-increasing population. World energy consumption continues to increase with the need of the population as a corollary. Most of the energy consumed comes from fossil fuels (oil, natural gas, coal, etc.) whose massive use can lead to the depletion of these reserves and to a real threat to the environment; renewable energies are increasingly used in the production of mass electrical energy and even industrial uses are increasingly considered.

The TVS power station designed in 2016 at the Laboratory of Electrical Engineering, Mecatronics and Signal Processing, allowed us to substitute the use of diesel fuel with solar energy in the production of electrical energy. It was a successful research work at the Master 2 level. The designed power station TVS is equipped with a parabolic capture system. Its installation, operation and maintenance are very expensive. Therefore, we are talking about innovating to make it perform.

During our thesis work, we propose to innovate the TVS system in its form and operation by moving from a parabolic capture system to a cylindro-parabolic collection system that will give us the opportunity to add a thermal storage equipment that will allow to improve its performance. We will finish this work by modeling the performance of the new plant. 


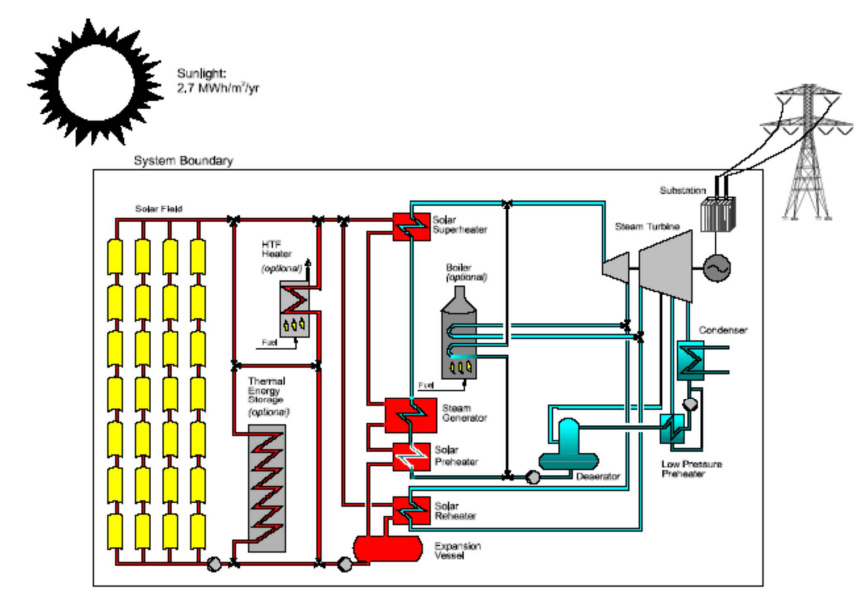

Figure 1. Configuration typique d'une centrale à collecteurs cylindroparaboliques.

\section{The Methodology}

\subsection{The State of the Art in This Sector}

The innovations today are very much about the modification of solar collection equipment. We have: Fixed sensors and mobile sensors. Perspectives of combining techniques to solve the problem of lack of sun at night are numerous and some are under development such as: thermal storage techniques with: molten salt, synthetic oils, air, liquid water or steam, composite ferrous materials, ceramics and many others. Concentration solar systems offer the possibility of producing electricity from solar energy, temperatures can easily exceed $500^{\circ} \mathrm{C}$ and the conversion efficiency is generally high.

The articles read evoke the research carried out and the innovations realized between 2013 and 2018 in the field of concentrated solar energy production namely:

In India in 2013, Albenga Solar developed a second generation of parabolic vats operating at temperatures above $400^{\circ} \mathrm{C}$. In the pit of the dish: the first floor heats up to $450^{\circ} \mathrm{C}$ and the second floor heats up to $550^{\circ} \mathrm{C}$, the performance has been evaluated and validated with satisfaction for one year. In Djibouti, in 2014, an experiment was conducted on a polycrystalline silicon photovoltaic solar power plant as part of a project to promote renewable energy, the solar power plant underwent stability control and performance monitoring. using these two methods: [8]

The standard performance-based method IEC 61724;

The method based on the PVUSA method under PTC conditions (PVUSA Test Conditions). [8]

In 2015, we discussed the work of Chinese researchers who studied by the method of numerical analysis the performance of linear parabolic receivers by tracing of solar rays (SRT) observation of the coolant flow, the heat transfer, the constraint thermal in a parabolic system and the profile of solar energy flow. The research resulted in the design of a new solar receiver. They improved the efficiency of the system they had previously designed, which indicated a failure of the glass seal on the metal.
In 2016, an article was published about a process for designing, simulating and manufacturing an integrated thermo-photovoltaic closed parabolic collector (ITPVCPC). These works have among others to innovate in the combination of the solar plates with a parable in composite materials. This made it possible to have two stages working respectively at $400^{\circ} \mathrm{C}$. and $550^{\circ} \mathrm{C}$. As a result, a substantial improvement in the efficiency of the system is obtained.

\subsection{Analyze Innovations in the Capture System}

These technologies make it possible to reach higher possible temperatures. Let's take a closer look at these different sensors.

\subsubsection{Mobile Sensors}

Mobile sensors are mobile devices designed to collect solar energy transmitted by radiation and communicate it to a heat transfer fluid (gas or liquid) in the form of heat. This heat energy can then be used directly for the heating of buildings, for the production of domestic hot water or to be transformed into mechanical movement in various industrial processes. So mobile sensors are needed when higher temperatures are required for the intended process. They use solar energy arriving on their large reflecting surface to send it on a smaller area called the concentration point where the temperature is very important.

The two most important concentration systems in the large-scale application are parabolic and cylindro-parabolic concentrators.

We note that this concentration technology is different from that of photovoltaic panels, which transform light (photons) into electricity. For these mobile sensors, we can usually quote:

\subsubsection{Sensors with Parabolic Trough Concentration (1 Axis) [4]}

This is the most widely used technology in large solar power plants for the production of electricity. The concentrator mirror is a cylinder of parabolic section and has only one direction of curvature (see figure 2). The concentration takes place on the line where the tubular receiver is placed in which circulates the coolant (water or oil) which can be heated up to $450^{\circ} \mathrm{C}$.

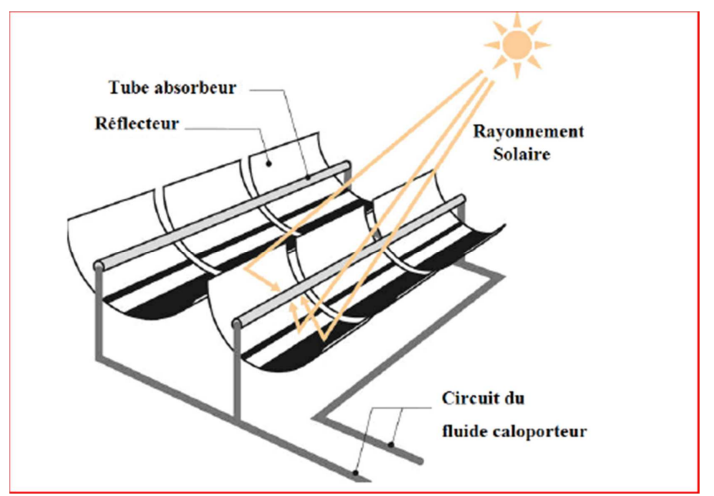

Figure 2. Diagram of a sensor with a parabolic trough concentration. 
Very large powers can be installed by interconnecting several sensors. The limitation in this case would come from the loss of loads and thermal losses which increase with the size of the installation. Figure 3 shows two examples of installations using this type of concentration sensor. The photo on the left shows the DHW plant in Jefferson County, Colorado, USA, where $100 \mathrm{~m} 2$ of small cylindro-parabolic sensors feed a 20-gallon hot water tank $\mathrm{m}^{3}$.

The photo on the right is nothing more than a glimpse of the sensor field of the Solar thermodynamic solar power station. Electric Generating System (SEGS) from Kramer Junction (California, USA). In the Mojave Desert, there are 9 solar power plants using cylindro-parabolic sensors for a total capacity of 354 MWelec. [10]

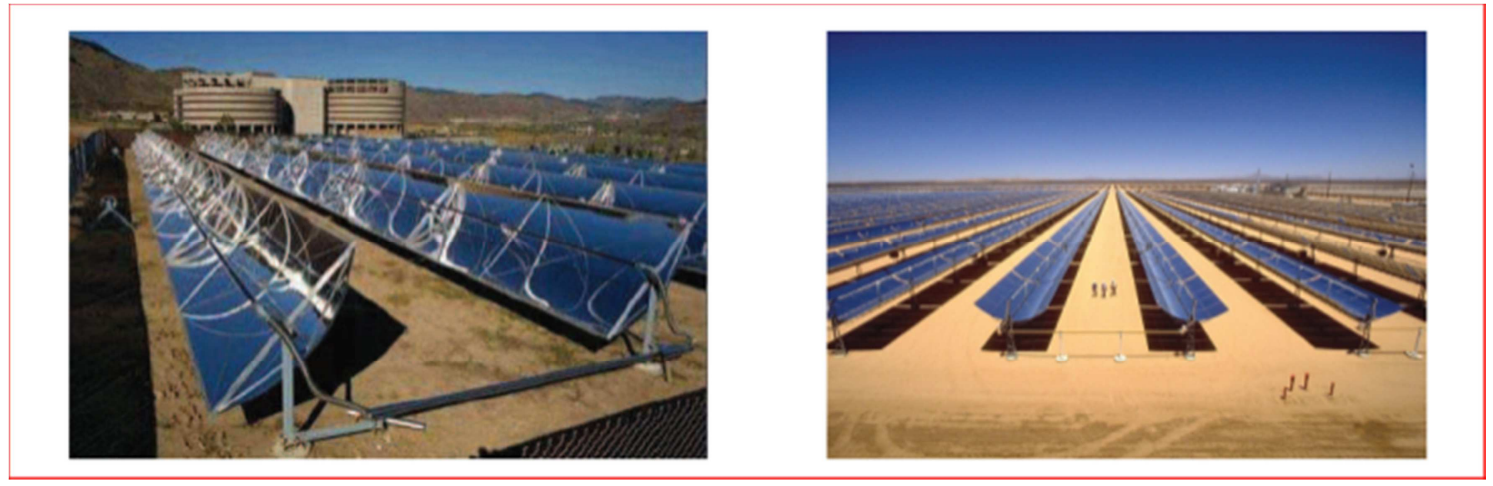

Figure 3. Photographs of two facilities using parabolic trough sensors.

\subsubsection{Fresnel Lens Sensors (1 Axis)}

Fresnel mirrored collectors offer an alternative solution to cylindro-parabolic sensors. This system uses flat mirrors arranged in parallel slats which slope to follow the sun and concentrate the rays on the tubular absorber placed above (Figure 8). The coolant (water, oil, steam) circulating in the absorber can be heated up to $400-450^{\circ} \mathrm{C}$.

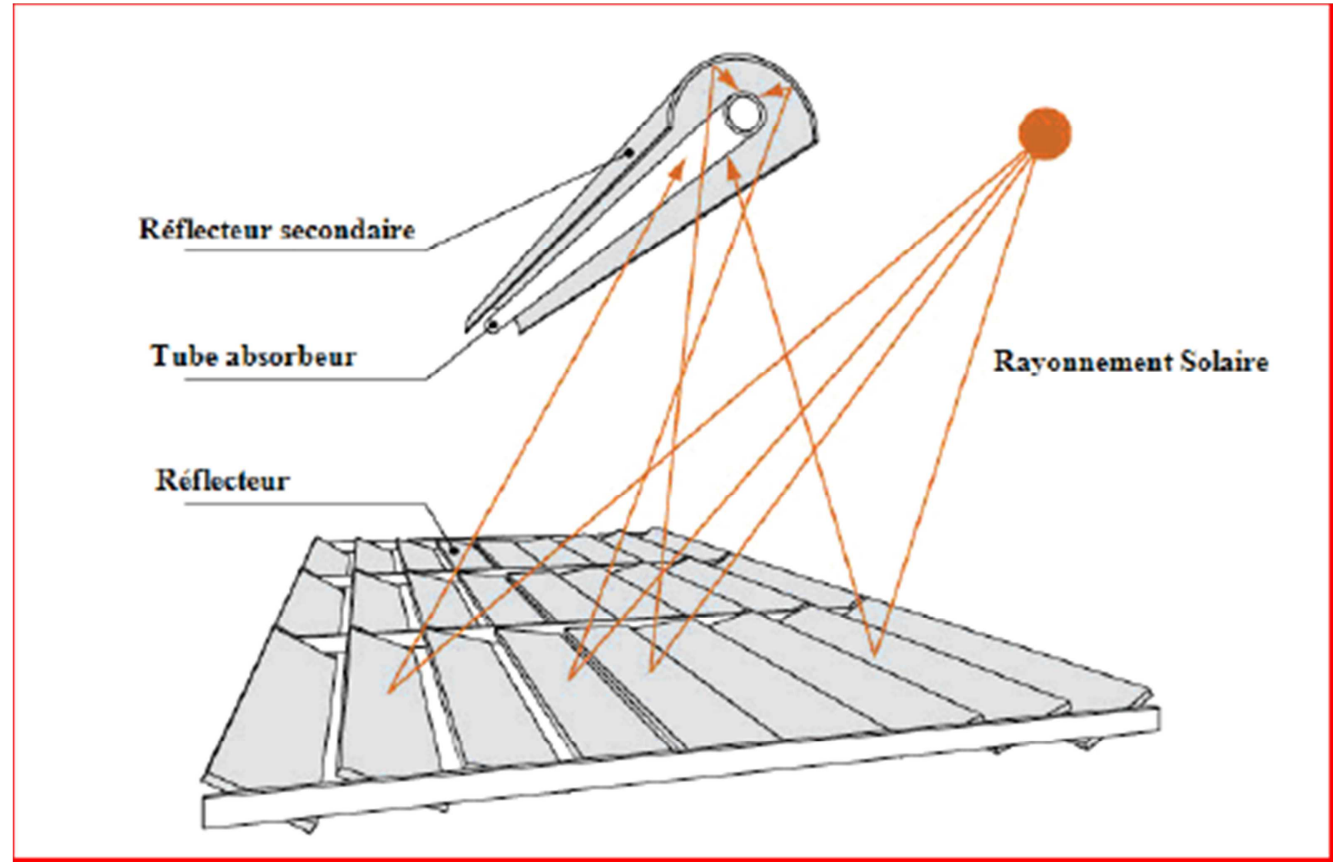

Figure 4. Schematic diagram of a Fresnel lens concentration sensor.

They are simpler and cheaper, but less efficient in terms of concentration. Figure 9 below shows two types of installations that can be envisaged with these concentration sensors using Fresnel lenses. In the photograph on the left, we can see a prototype of micro-power plant (Bergamo, Italy) developed by the German company PSE AG and intended to equip the roofs of the collective buildings. The one on the right gives an overview of the Fresnel mirror field, located in Tabernas in Andalusia (Spain), with a power of $800 \mathrm{~kW}$ thermal. 


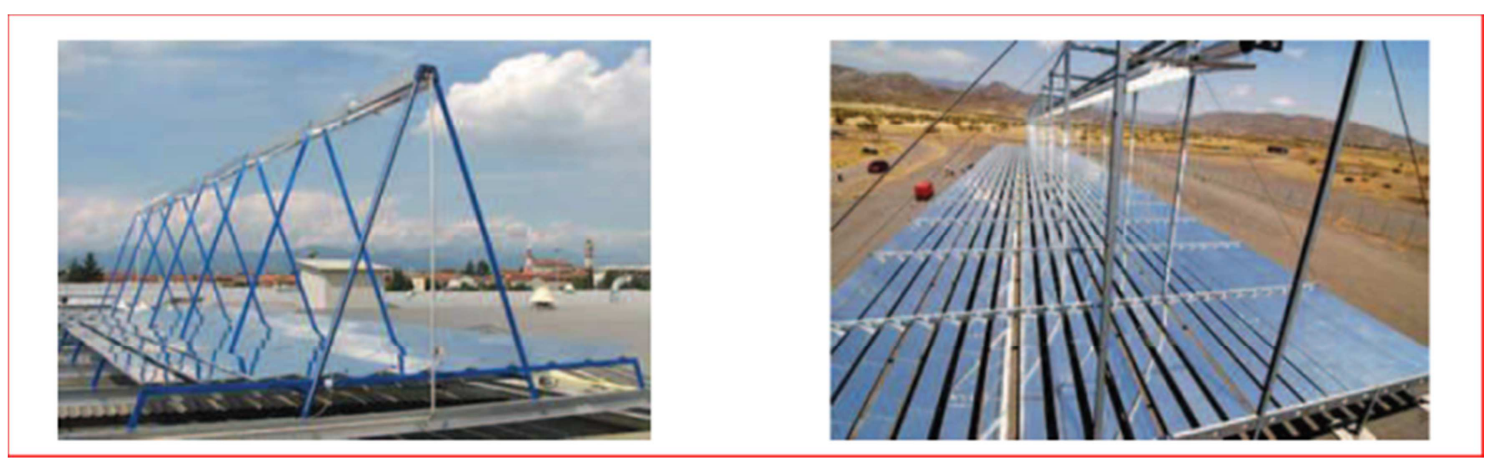

Figure 5. Photographs of two installations using Fresnel lens sensors.

\subsubsection{Parabola of Revolution (2 Axes)}

It is the ideal concentrator for concentrating the sun's rays (figure 10). On the other hand, it is essential to orient the axis of the parabola in the direction of the sun, so that the reflected solar rays converge towards the focus (zone of maximum concentration).

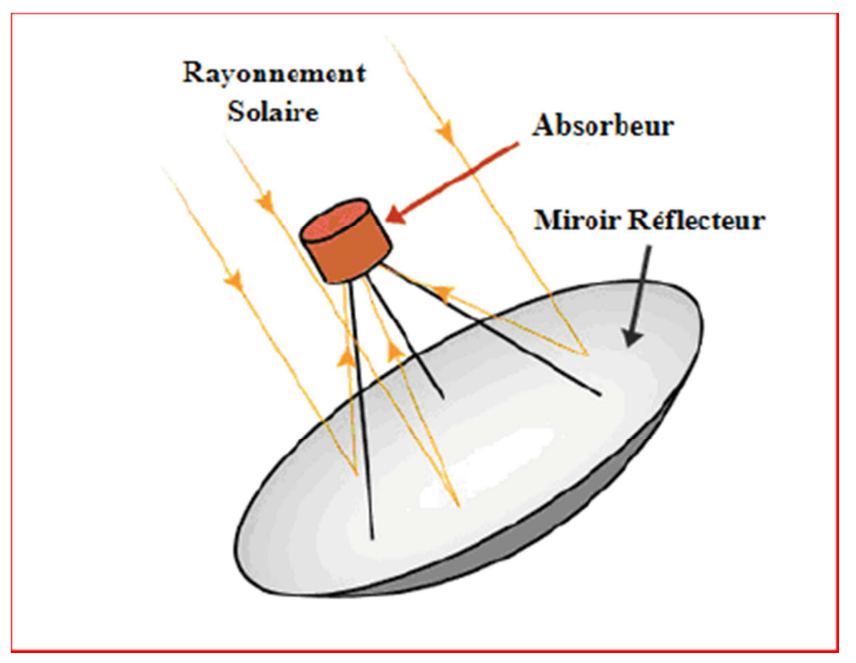

Figure 6. Schematic diagram of a parable of revolution.

The need to mobilize the dish in two axes of rotation to ensure the continuation of the sun leads to a limitation of the unit dimension of this type of installation. As a result, the current area of these parabolas is 50 to $100 \mathrm{~m}^{2}$ (the largest being $500 \mathrm{~m}^{2}$ ). The average concentration factor obtained in the home generally exceeds one thousand and allows to reach very high temperatures (more than $800^{\circ} \mathrm{C}$ ).

NB: In general, the idea of using a parabolic surface comes from the fact that it is stigmatic (gives the output of the parabola a beam converging at a point) for the points at infinity on its axis. According to the laws of reflection, every ray of light parallel to the axis of the parabola is reflected by the parabola along a straight line passing through the focus. So, the parabola focuses all the reflected rays at a point called "focus". This implies that these concentrators must follow the movement of the sun. Parabolic reflector systems can reach higher temperatures (up to $1500^{\circ}$ ) on the absorber.

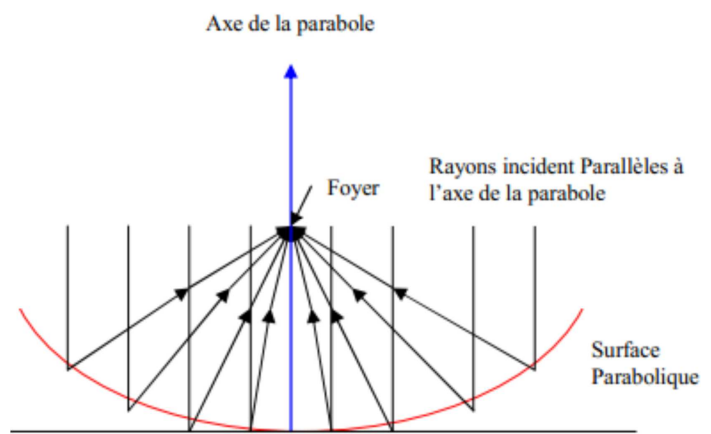

Figure 7. Optical system of a parabolic surface.

\subsubsection{Absorber of the Parabolic Sensor}

According to their transfer surface, the absorbers of the parabolic sensor are classified into 2 categories:

i. External surface: There are several possible configurations: plane, cylindrical, conical or spherical, dependent on the distribution, intensity of flow, temperature and application. This type of absorber generally applies in the temperature range of the order $300-400^{\circ} \mathrm{C}$ maximum.

ii. Internal surface or cavity: This type of absorber is well suited for the case where the intensity of the flow and the working temperature are high. The energy flows.

Concentrate enters the absorber through the opening whose surface is usually 5 to 10 times less than that of the transfer surface in the cavity. It is an effective way to increase the absorption coefficient and reduce losses. [2]

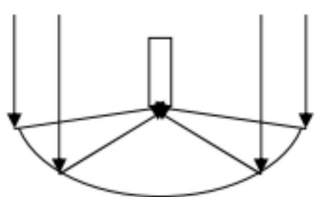

Surface interne, Cavité

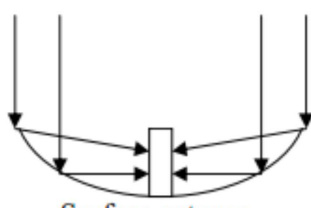

Surface externe
Figure 8. Absorber Categories.

The cylindro-parabolic reflectors are "U" shaped systems. They concentrate the sun's rays on an absorber tube located along the focal length of the reflector. Sometimes a clear glass tube surrounds the absorber tube to reduce heat loss. These concentrators often use a single-axis or dual-axis solar tracking system. The temperatures of the absorber can reach $400^{\circ} \mathrm{C}$. [2] 


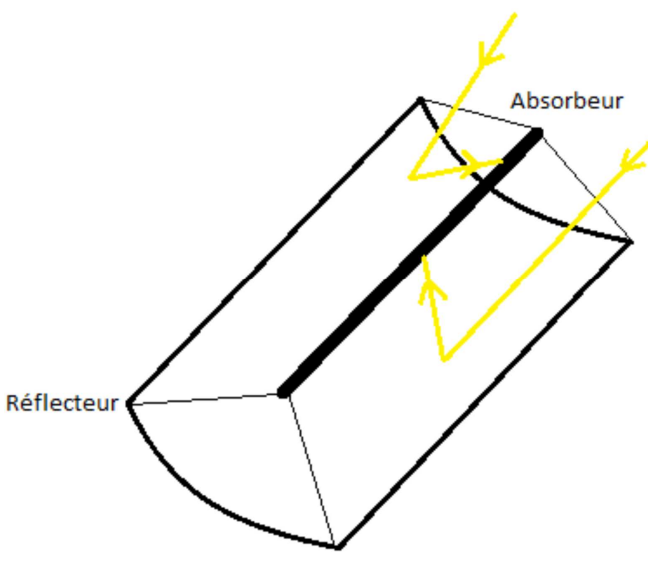

Figure 9. Parabolic trough sensor.

\subsubsection{Parabolic Tower}

The goal of a concentrator system is, as the name suggests, to focus the sun's rays from a relatively large area (mirrors) to a smaller area (receiver).

The geometric concentration factor is the ratio of the total area of collection of the mirrors to the receiving surface of the concentrated rays (Equation 1).

$$
\mathrm{FC}=\frac{\text { Acoll }}{\text { Arec }}
$$

The higher the concentration factor, the higher the flux density impacting the receiver, and therefore the higher the temperature reached by the receiver $\mathrm{Tr}$ can be high. A high temperature makes it possible to achieve theoretical thermodynamic efficiencies (Carnot efficiency, Equation 2) higher during Carnot conversion, Equation 2) higher when converting heat into electricity. [4]

$$
\eta \text { Carnot }=1-\frac{\text { TfroidAcoll }}{\text { Tchaud }}
$$

The efficiency of the plant is well below this theoretical limit: optical losses occur at the heliostat field or collectors, heat losses in receivers, pipes, storage (if present) and heat exchangers, and mechanical and thermal losses in the power group. In the end, we define the overall performance of the plant

as the ratio of the output electric power to the solar power input of the collection system (Equation 3) [4]

$$
\eta \text { globale }=\frac{\text { Pél }}{\text { Psol }}=\frac{\text { Pél }}{\text { DNI.Acoll }}
$$

\subsubsection{Thermal Storage Materials}

Thermal conservation materials are added to the collectors to keep solar power generation out of the sun.

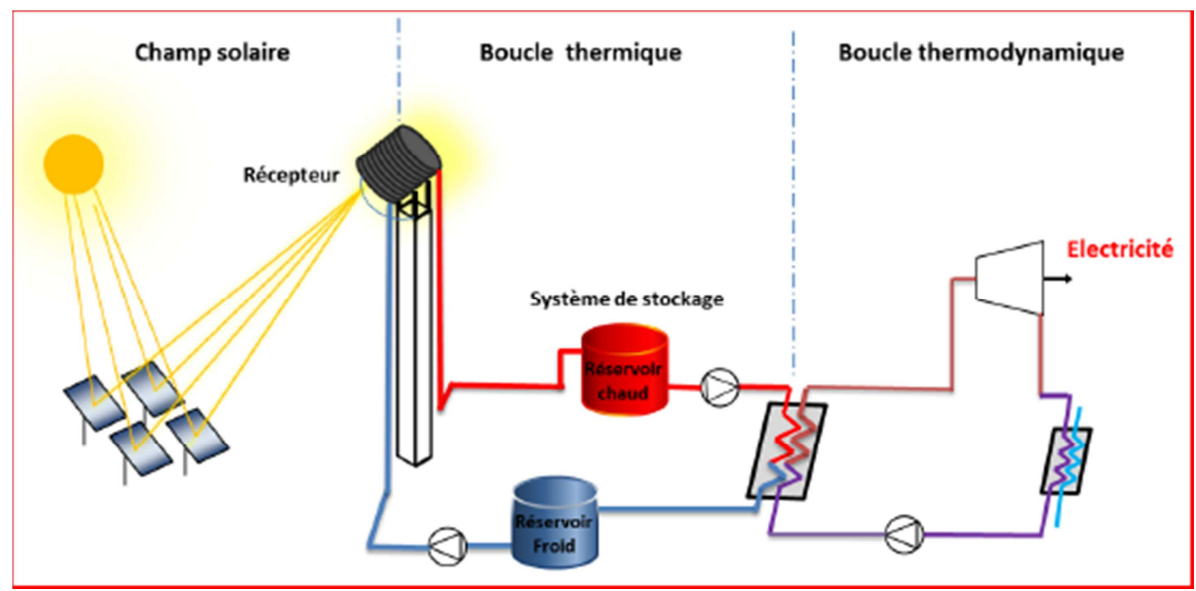

Figure 10. Simplified diagram of the direct active storage system with two tanks in one central tower.

\subsubsection{Links Between Temperature and Innovations [5]}

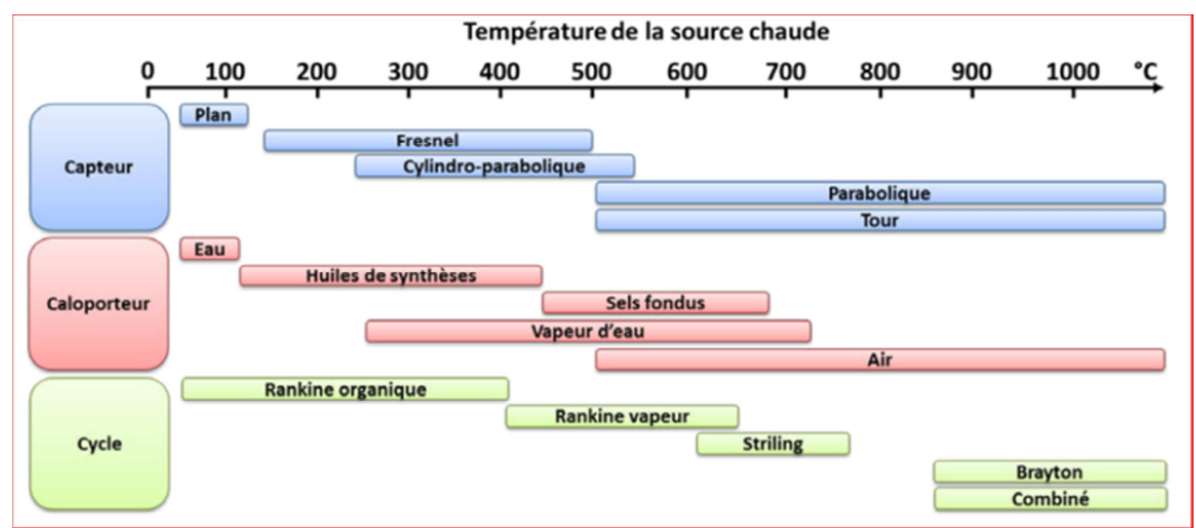

Figure 11. Relation between Sensor-heat carrier-cycle [5]. 
We note that the sensors, the heat transfer fluids and the thermal cycles have a cause and effect link with the temperatures detected. Heat transfer fluids (molten salts, water vapor, air) and concentration sensors are in the high temperature domain. At stage the Rankine steam cycles or the Sterling or Brayton or Combined cycle are recommended.

\section{As to Conclusion}

We have analyzed the main innovations brought to the concentration sensors and their parameters influencing the solar concentration such as the geometric concentration factor which is the ratio between the total surface of collection of the mirrors and the surface of reception of the concentrated rays.

With regard to the production of electrical energy by various devices, today's innovations relate a lot to the modification of solar collection equipment. We analyzed: Fixed sensors and mobile sensors. The prospects for combining techniques to solve the problem of lack of sun at night are numerous and some are being developed such as: thermal storage techniques with as coolant: molten salt, synthetic oils, air, liquid water or vapor, composite ferrous materials, ceramics and many others.

Concentrated solar systems offer the possibility of producing electricity from solar energy, temperatures can easily exceed $500^{\circ} \mathrm{C}$ and the conversion efficiency is higher and higher. The production of solar electricity attracts the industrial world. For Africa, the objectives of the future in thermal conservation, should focus on local materials such as clay or sand which are being evaluated, already elsewhere.

The expression "solar thermodynamics" designates all the techniques aimed at transforming the energy radiated by the sun into heat at sometimes very high temperatures. Finally, it is transformed into mechanical or electrical energy through a thermodynamic cycle. These techniques are essentially being evaluated. The cost of installing renewable energy remains very high for many African countries, so African countries must join their efforts in partnership or in regional effort to carry out renewable energy projects in Africa where the potential is very high.

\section{Acknowledgements}

Thank you to my professors who supervise my thesis and to others who took the opportunity to participate in the evaluation of this work of publication of this submitting article.

\section{References}

[1] GENERAL ARTICLE Exploiting Sun's Energy Effectively as a Source of Renewable Energy Deepa Khushalani www.researchgate.net > publication > 324913787

[2] Mathematical Modeling and Simulation of Solar Sensors Yaici, Malika; promotrice; Iberraken, Aghiles; Alili, Riad www.univ-bejaia.dz/dspace/handle/ 123456789/9241.
[3] Experimental monitoring of the performance of a photovoltaic solar power plant in Djibouti www.researchgate.net/publication/281992390_Suivi_experim ental_des_performances;_.

[4] Thomas Fasquelle Modeling and experimental characterization of a cylindrical-parabolic solar loop incorporating thermocline-type storage. Other. University of Perpignan, 2017. Français.

[5] Estimating the Potential of Concentrated Thermodynamic Solar Technology in Non-Desert Climate - Application à La Réunion: by Emeric TAPACHÈS.

[6] University of Liège Faculty of Applied Sciences The Concentrating Solar Power Plants Quoilin Sylvain https://fr.calameo.com/books/000419771243d279a6bd9.

[7] Direct steam generation in parabolic trough collectors $\mathrm{M}$. Alguacila, C. Prietoa, A. Rodrigueza, J. Lohra a Abengoa Solar. Calle Energía Solar, 1, Sevilla 41014, Spain.

[8] Renewable and Sustainable energy Review in India Recent developments of solar energy in India: Perspectives, strategies and future egoals Subhojit Dawnn, Prashant Kumar Tiwari, Arup Kumar Goswami, Manash Kumar Mishra.

[9] SOLAR CONCENTRATION PLANT FOR RURAL ENVIRONMENT IN NIGER: STUDY OF THE CONCENTRATOR AND ECONOMIC AND ENVIRONMENTAL ASPECTS International Institute of Engineering Rue de la Science - 01 BP 594 - Ouagadougou 01 - BURKINA FASO - Mail: 2ie@2ie-edu.org - www.2ie-.

[10] The Concentrating Solar Power Plants. University of Liège Faculty of Applied Sciences, Quoilin Sylvain https://fr.calameo.com/books/000419771243d279a6bd9.

[11] Manuscrit_Doctorat_Emeric_Tapachès_Avril2015.

[12] Kennedy, J., Eberhart, R., Shi, Y., Swarm Intelligence, 2001, Academic Press, Inc.

[13] S. Safari, M. M. Ardehali, M. J. Sirizi "Particle swarm optimization based fuzzy logic controller for autonomous green power energy system with hydrogen storage" Global Conference on Renewable energy and Energy Efficiency for Desert Regions 2011 "GCREEDER 2011", Energy Conversion and Management, Volume 65, January 2013, Pages 41-49.

[14] Randy L. Haupt, Sue Ellen Haupt" Practical Genetic Algorithms" second edition, 1998.

[15] Seth B. Darling, Fengqi You, Thomas Veselka, and Alfonso Velosa "Assumptions and the Levelized Cost of Energy for Photovoltaics", Created using the RSC ARTICLE templates (VER. 3.1).

[16] IRENA Working Paper, "RENEWABLE ENERGY TECHNOLOGIES: COST ANALYSIS SERIES", Volume 1: Power.

[17] Sector, Issue 4/5 Solar Photovoltaics, June 2012.

[18] Bogdan S. Borowy Ziyad M. Salameh "Methodology for Optimally Sizing the Combination of a Battery Bank and PV Array in a Wind/PV Hybrid" IEEE Transactions on Energy Conversion, Vol. 11, No. 2, June 1996. 